\title{
Social interactions among adult male rats after early undernutrition
}

\author{
By T. S. WHATSON, J. L. SMART AND J. DOBBING \\ Department of Child Health, University of Manchester, Manchester \\ (Received I7 December 1973 - Accepted 19 February 1974)
}

\begin{abstract}
1. Developing rats were growth-retarded during gestation and the suckling period by underfeeding their mothers from mating. After weaning, all animals were fed ad lib.

2. At 18 weeks each male was paired with another male for 10 min on 4 consecutive days. Tests $I$ and 2 were with males of like-treatment group and tests 3 and 4 with males of unliketreatment group.

3. Pairs of previously undernourished rats boxed and fought more often than pairs of controls. In the mixed pairings of tests 3 and 4 the previously underfed animals initiated contact more frequently than did their control partners.

4. Evidently there is a lasting effect of early nutritional deprivation on inter-male social behaviour, especially when both of the animals interacting are of the previously undernourished type.
\end{abstract}

Malnourished infant rats perform less social grooming than well-fed controls and are more likely to attack one another (Fraňková, 1973). Likewise Levitsky \& Barnes ( 1972 ) noticed that 3 - to 7 -week-old malnourished rats engaged in 'considerably more fighting behaviour than their well-nourished controls' during frequent I h 'play' periods.

Whether such differences outlast lengthy nutritional rehabilitation is not clear. Levitsky \& Barnes (1972) did observe some aspects of male-male interaction among their rats 10 weeks after the end of nutritional restriction but they were principally interested in the important question of nutrition-environment interactions and have little to say about the influence on social behaviour of nutrition per se. The present experiments were carried out to investigate the effect of early nutritional deprivation on the social interactions of male rats in adulthood.

\section{METHODS}

Rats. Female rats of the black-and- white hooded Lister strain, which had previously borne one or two litters, were housed three to a cage with one male. Day of mating was determined by examination of vaginal lavages for sperm.

Females were housed singly from mating and allocated to one of two treatment groups: control or undernourished. Control mothers had unlimited access to a goodquality diet at all times (Breeding Diet for Rats and Mice, Oxoid Ltd, Southwark Bridge Road, London SEI $9 \mathrm{HF}$ ). The composition of the diet has been described in detail elsewhere (Smart, Dobbing, Adlard, Lynch \& Sands, 1973). Undernourished dams received a limited amount of the same food throughout pregnancy and lactation. This consisted of $10 \mathrm{~g} / \mathrm{d}$ during gestation and 15,20 and $25 \mathrm{~g} / \mathrm{d}$ respectively during 
the first 3 weeks after parturition. They continued to receive $25 \mathrm{~g} / \mathrm{d}$ until their litters were weaned. These amounts represent about half the intake of control mothers at the same stages. Water was always available for both groups.

The litters were weighed and sexed at birth and reduced, where possible, to six males and two females, but always to eight pups. They were weaned at $25 \mathrm{~d}$, from which time all animals were fed $a d l i b$. The sexes were separated at $35 \mathrm{~d}$ and the males caged in littermate groups of two or three. They remained in these groups until they were caged singly at approximately $\mathrm{I}_{4}$ weeks. Habituation was begun 3 weeks later. A total of thirty-nine male rats were used: nineteen previously underfed rats $(\mathrm{PU})$ from eight litters and twenty controls (C) from seven litters.

Illumination of the animal room was on a $12 \mathrm{~h}$ white-light, $12 \mathrm{~h}$ deep red-light cycle. Testing was carried out in red light.

Apparatus. The testing chamber was a grey hardboard box, $330 \times 300 \times 330 \mathrm{~mm}$ high, with the front and top made from clear Plexiglass. The floor was covered with the same absorbent material (Sterolit; Engelhard Minerals and Chemicals Corporation, Menlo Park, Edison, New Jersey, USA) as the floors of the home cages. Observations were made indirectly through the Plexiglass front with the aid of a closed-circuit television system (Shibaden Electric Company Ltd, Japan) and each test was recorded on videotape. Two observers watched a monitor in a room adjacent to the test room and recorded aspects of the animals' behaviour on manual counters.

Procedure. Each animal was placed alone in the observation box for 10 min on each of $6 \mathrm{~d}$ prior to testing. After these habituation sessions, each animal was observed in the observation box with another animal during 10 min sessions on 4 consecutive days. In tests $I$ and 2 strange animals of like-treatment group were paired and in tests 3 and 4 strange animals of unlike-treatment group were put together. No two rats met more than once and littermates were never paired. The order in which the animals were tested was varied randomly from day to day. Faecal boluses were removed from the observation box and counted after each habituation or test session. Urine was absorbed by the layer of Sterolit which was not changed throughout the habituation and test sessions. It was assumed that a background of odours from the many previous occupants would thus be produced, against which any new odour would be inconspicuous.

Each observer watched a different rat and scored the incidence of four types of social interaction. (Interobserver reliability for all responses combined, $r=0.97$.) At a later time, one of the observers scored the incidence and duration of other behaviours from the videotape recording.

Statistical analysis. The Ist two and and two tests were treated independently from the point of view of statistical analysis. The unit of information on which analysis was carried out was, for each rat, the sum of its scores with two partners of the same (like) treatment group as itself (tests $I$ and 2) or the sum of its scores with two partners of unlike-treatment group (tests 3 and 4 ). All statistical analysis was by the MannWhitney $U$ test (two-tailed) except where stated otherwise. For comparisons in which more than half the scores were ties an appropriate correction was made (Siegel, 1956).

Terminology. The following are definitions of terms used in describing the behaviour 
Table r. Body-weights $(g)$ of control $(C)$ and previously undernourished $(P U)$ rats at four ages

(Mean values and standard deviations; no. of rats in parentheses)

\begin{tabular}{|c|c|c|c|c|}
\hline & \multicolumn{4}{|c|}{ Age } \\
\hline & Birth & $25 \mathrm{~d}$ & $90 \mathrm{~d}$ & $\mathrm{r} 54 \mathrm{~d}$ \\
\hline $\mathrm{C}$ & $\frac{5.5 \pm 0.6}{(37)^{*}}$ & $52 \cdot 7 \pm 7 \cdot 2$ & $302 \pm 26.8$ & $\begin{array}{c}426 \pm 28 \cdot 0 \\
(12) \dagger\end{array}$ \\
\hline PU & $4 \cdot 9 \pm 0.5^{ \pm}$ & $\begin{array}{c}18 \cdot 5 \pm 4 \cdot 9 \\
(32)^{*}\end{array}$ & $248 \pm 33^{\circ} \circ$ & $\underset{\text { (II })}{278}$ \\
\hline $\begin{array}{l}\text { Statistical } \\
\text { significance of } \\
\text { difference between } \\
\text { meanst }\end{array}$ & $P<0.001$ & $P<0.00 \mathrm{r}$ & $P<0.002$ & $P<0.001$ \\
\hline
\end{tabular}

of the rats: sniff, the orientation of the head of one rat towards another rat in close proximity to it; allogroom, the nibbling or licking of the fur of another rat; submit, the animal lies on its back with its paws outstretched whilst another animal takes up the 'aggressive posture'; aggressive posture, the animal stands over and in contact with one in the submit posture; mount, one animal stands behind and against the back of another, clasping the flanks with its forepaws (this is usually accompanied by pelvic thrusts); box, both animals stand on their hind legs facing one another as if boxing, and stretch their noses upwards; fight, both animals grapple one another and leap, roll and jump about as one; initiator, an animal which approaches and makes contact with another; latency, time from the beginning of a test to the occurrence of a particular behaviour pattern (no account being taken of which animal of a pair performs the behaviour pattern in question).

\section{RESULTS}

\section{Body-weight}

At birth, $25 \mathrm{~d}, 13$ weeks and 22 weeks the previously undernourished rats were significantly lighter than the control rats (Table I).

\section{Social behaviour}

Median values have been used in preference to means in Tables 2 and 3 because this is 'the statistic most appropriate for describing the central tendency of scores in an ordinal scale' (Siegel, 1956). The frequency distributions for most measures were far from Gaussian.

Tests $\mathrm{x}$ and 2. The PU rats fought and boxed with one another more often than did the controls (Table 2). They also defaecated more frequently during the tests. Movement about the observation box was not measured, but the subjective impression was that the PU rats were much more active, in terms of distance travelled, than $\mathrm{C}$ rats.

Tests 3 and 4 . Here, by contrast with the previous tests, the comparison between the 
Table 2. Social interactions between male rats; tests $\mathrm{I}$ and 2 : interactions between like pairs of control $(C)$ or previously undernourished $(P U)$ rats

(Median values with ranges in parentheses; sum of no. of interactions for each rat with two like partners)

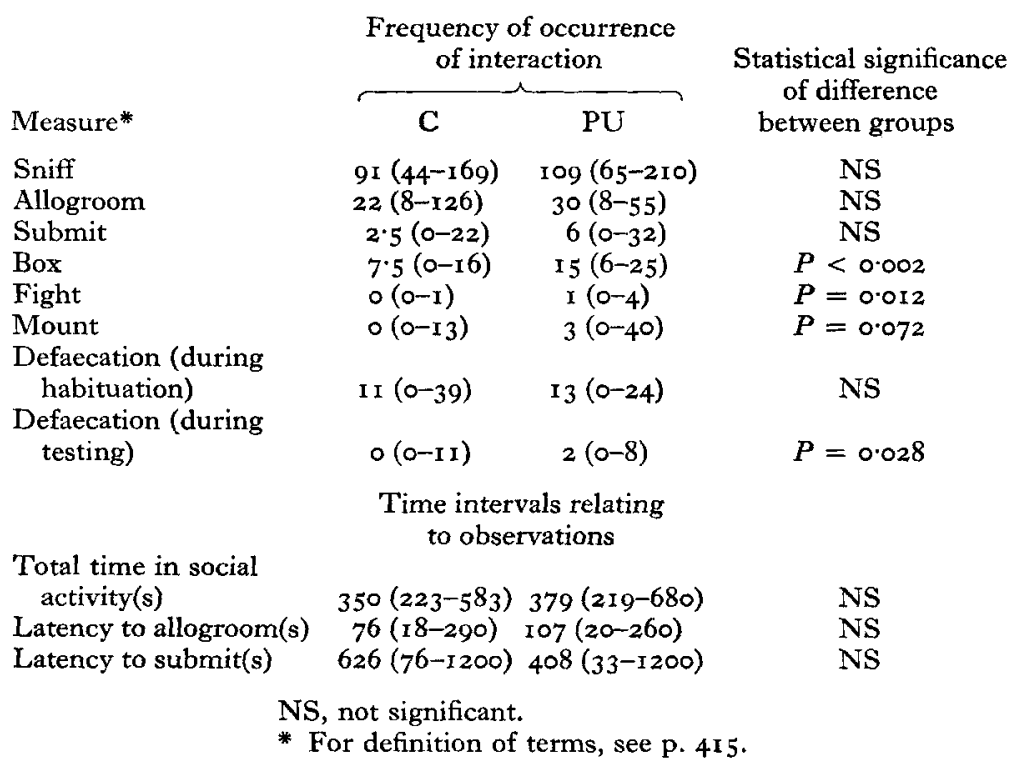

treatment groups is based on the results of confrontations between $\mathrm{C}$ and PU animals. In this situation it is possible to compare $\mathrm{C}$ with $\mathrm{PU}$ rats only for those activities which do not require equal participation by both animals. Activities in which both partners actively participate, such as box and fight, cannot be compared between participants. By definition both animals must receive the same score. These measures and total time in social activity are therefore absent from Table 3 . (However, they were scored to allow comparison with behaviour in tests $I$ and 2. See later discussion.) Latencies were not recorded for each individual animal, nor were defaecation scores noted.

In these confrontations between rats of different treatment groups there was only one significant difference in behaviour (Table 3 ). PU rats initiated social acts more often than did the controls. Whilst there was no significant difference in the absolute number of submit events by $\mathrm{C}$ and $\mathrm{PU}$ rats, for any given pair the $\mathrm{PU}$ rat tended to submit more frequently to the $\mathrm{C}$ rat, than the other way around $(P<0 \cdot \mathrm{I}$; sign test, two-tailed).

During the later stages of the experiment a note was made of which type of animal was the first to allogroom. Information was collected from sixteen tests, but no trend emerged.

Change in behaviour over tests $\mathrm{I}-4$. Some information on the influence of type of partner on social behaviour can be obtained by comparing behaviour with a partner of like treatment group in tests $I$ and 2 to that with a partner of unlike treatment group in tests 3 and 4 . For instance, do $\mathrm{C}$ rats behave differently to $\mathrm{PU}$ rats than they 
Table 3. Social interactions between male rats; tests 3 and 4 : mixed pairs of control $(C)$ and previously undernourished $(P U)$ rats

(Median values with ranges in parentheses; sum of no. of interactions for each rat with two unlike partners)

$\begin{array}{lccc}\text { Measure of interaction* } & \begin{array}{c}\text { Frequency of occurrence } \\ \text { of interaction }\end{array} & \begin{array}{c}\text { Statistical significance } \\ \text { of difference } \\ \text { between groups }\end{array} \\ \text { Sniff } & \mathrm{C} & \mathrm{PU} & \mathrm{NS} \\ \text { Allogroom } & 106(55-182) & 130(57-240) & P<0.1 \\ \text { Submit } & 27(6-40) & 36(14-66) & \text { NS } \\ \text { Mount } & 5(0-26) & 6(0-23) & P=0.08 \\ \text { Initiatef } & \mathrm{I}(0-\mathrm{Ir}) & 5(0-26) & P<0.05\end{array}$

NS, not significant.

* For definitions of terms, see p. 415 .

$\dagger$ This result was obtained by observing the last twenty-four consecutive bouts out of the possible thirty-eight.

do to their own kind? (The Wilcoxon matched-pairs, signed-ranks test, two-tailed, was used for these comparisons.)

Control rats responded similarly to both $\mathrm{PU}$ and $\mathrm{C}$ partners. They exhibited no significant changes in the incidence of any activity. Previously undernourished rats, however, allogroomed $(P<0.01)$ and mounted $(P<0.05) \mathrm{C}$ rats more frequently than they had done animals of their own treatment group, and boxed with them less often $(P<0.01)$.

Both $\mathrm{C}$ and $\mathrm{PU}$ rats had shorter latencies to allogroom $(P<0.02$ and $P<0.01$ respectively) and to submit $(P<0.01$ and $P<0.02$ respectively) when paired with animals from a different treatment group than when paired with animals from the same treatment group.

\section{DISCUSSION}

The principal finding was that pairs of previously undernourished rats boxed and fought more often than pairs of control rats. This difference is in the same direction as those reported by Fraňková (1973) and Levitsky \& Barnes (1972) for infant and adolescent rats malnourished at the time of testing, and indicates that the heightened aggressive propensity outlasts by far the period of nutritional deprivation. However, unlike Fraňková's malnourished weanling rats, the previously underfed animals of the present experiment were never seen to behave in any completely aberrant way. All behaviour patterns observed in our previously undernourished animals were also observed in the controls. The difference was one of frequency of performance, not of kind.

Comparison of the present results with those of Levitsky \& Barnes (1972) is difficult because they do not quote the significance of differences due to early nutritional treatment. Nevertheless, it is clear from their Fig. 2 that two of their previously malnourished groups spent more time fighting than their appropriate controls. These were the groups whose early rearing conditions most resembled those of the rats in the present experiment. Our rats' early environment was probably more stimulating than 
Levitsky and Barnes's 'control experimental' condition but less so than their 'stimulating' condition.

Each rat was subjected to four social behaviour tests, the Ist two with rats of the same treatment group and the 2 nd two with rats of the other treatment group. Hence, any changes in behaviour between the ist and 2 nd sets of tests can be interpreted either as effects of type of partner (as suggested in the Results) or as effects of experience. To have conclusively sorted out the two possible effects half of the animals would have had to be tested as in the present experiment and half in the reverse order, with an unlike partner first and then with a like partner. However, this was not a principal aim of the present experiment. Presumably changes between tests $I$ and 2 and tests 3 and 4 in the same direction for both treatment groups are likely to be a function of experience of the test situation. Hence the shorter latencies to allogroom and submit for both $\mathrm{C}$ and PU rats on tests 3 and 4 are probably best interpreted as effects of experience.

The frequency of social acts by control rats did not differ significantly whether they were paired with other controls or with previously underfed animals. However, PU rats allogroomed and mounted $C$ rats more often than they did rats of their own treatment group and boxed with them less frequently. It can be argued that these changes were a function of the type of partner. Any social interaction, by definition, must involve both partners, but the degree of active participation by the two animals differs widely depending on the kind of interaction. Boxing, for instance, requires the active participation of both rats, whereas with allogrooming and mounting one rat assumes an active role and the other rat a passive one. Even though the passive role may be the adoption of a specific posture, the passive animal is, nevertheless, clearly being acted upon and is at that time the less active animal. In view of the higher frequency of boxing in $\mathrm{PU}$ pairs than in $\mathrm{C}$ pairs, it is not surprising that frequency of boxing by $P U$ rats declined when they were paired with controls. Presumably the level of mutual stimulation in the mixed $\mathrm{C}$ and PU pairs was lower than it had been in the PU pairs.

Previously undernourished rats have been found to be more active than well-fed controls in terms of movement about their living space (Slob, Snow \& de NatrisMathot, 1973) and in a familiar observation box (Smart, 1974). The subjective impression in the present experiment was the same. Hence, PU rats in the mixed pairs were probably in the company of a less active animal than they had been in the likepair situation, an animal which may therefore have been more amenable to being allogroomed or mounted.

In general, aggressive acts were more common in $\mathrm{PU}$ pairs than in $\mathrm{C}$ pairs. When $\mathrm{C}$ and $\mathrm{PU}$ rats were paired the PU rat was the more likely to initiate social behaviour and tended more often to be the active partner in any interaction. These findings are consistent with the suggestion that previously underfed animals have a lowered hreshold of arousal (Dobbing \& Smart, 1974).

We wish to thank Miss Rhona Welch who helped with the observations. We are grateful to the Medical Research Council and the National Fund for Research into Crippling Diseases for financial support. 


\section{REFERENCES}

Dobbing, J. \& Smatt, J. L. (1974). Br. med. Bull. 30, 164.

Fran̆ková, S. (1973). Devl Psychobiol. 6, 33.

Levitsky, D. A. \& Barnes, R. H. (1972). Science, N. Y. 176, 68.

Siegel, S. (1956). Nonparametric Statistics for the Behavioral Sciences p. 123. New York: McGraw-Hill.

Slob, A. K., Snow, C. E. \& de Natris-Mathot, E. (1973). Devl Psychobiol. 6, 177.

Smart, J. L. (1974). Devl Psychobiol. 7 (In the Press.)

Smart, J. L., Dobbing, J., Adlard, B. P. F., Lynch, A. \& Sands, J. (1973). F. Nutr. 103, I327. 